\title{
Combined GPS and motion-tracker data for activity levels and various route selections in everyday travel
}

\author{
Kaito Yoshida $^{\mathrm{a},}{ }^{*}$, Madoka Nakajima ${ }^{\mathrm{a}}$, Takashi Morita ${ }^{\mathrm{b}}$ \\ ${ }^{a}$ Kokusai Kogyo Co., Ltd, kaito_yoshida@kk-grp.jp, madoka_nakajima@kk-grp.jp, \\ ${ }^{b}$ Professor Emeritus, Hosei University, morita@hosei.ac.jp \\ * Corresponding author
}

\begin{abstract}
This study used location and physical-activity data to test hypothesis that Tokyo's residents exercise more because they walk to and from public transit stations for daily trips. An activity tracker and a mobile app were used by ten subjects over 48 days to collect data. Analysis of the dataset showed that on an average, all subjects walked over 10,000 steps per day and $\sim 40 \%$ of trips were taken in outdoor urban environments. Results also revealed that the subjects did not always take the shortest path between the origin and destination of a walking trip. These results suggest that urban residents choose routes of travel based on both internal and external factors, including the subjective effects of street design and personal preference.
\end{abstract}

Keywords: Urban design, Physical activity, Location-based data, Route selection, Shortest path

\section{Introduction}

Adoption of automobiles reduces the number of trips that urban residents take on foot. As a measure against the unregulated presence of cars, cities have increased investment in public transit such as trains and buses. Walking to and from public transit stations promotes physical activity and public health (ref. Oba T, et al., 2013). If public transport is readily available and effective, more supplementary trips will be accomplished by walking. Thus, city planners interested in public health should consider how movement patterns are influenced by transit systems and road design. However, the commonly administered movement survey in Japan, namely the person-trip survey, does not offer much detail about movement in a city. This study collected finegrained data from a small set of subjects to reveal the details of typical daily movement within Tokyo's metropolitan area, considering that public transportation is the main mode of transportation therein. In addition, this study aimed to investigate how subjects might choose paths by criteria other than taking the shortest time or distance to reach a destination.

\section{Methods}

We collected data from several sources to gain insights about daily movements and physical activity within the urban environment of Tokyo. Ten study subjects used the wearable activity tracker charge HR (e.g. Fitbit, Inc., "charge HR") and the mobile app Moves (e.g. ProtoGeo Oy, "Moves"), which records GPS data. The origin and destination of all trips taken by the subjects on foot were extracted from this data, and the amount of physical activity undertaken in each trip was calculated. The amount of activity was divided into contexts based on the GPS data so that the group trips can be categorized into indoor and outdoor periods. Furthermore, we extracted the routes subjects used and compared them against the structural features of the roads in the area.

\section{Investigation and analysis}

\subsection{Results of the investigation}

The ten subjects included six males and four females; data were collected over roughly two months from each subject. We judged whether the movement paths were typical of the subjects' everyday experience, based on whether the subjects were closer to their workplace or residence during the trips. Attributes of the subjects and a summary of the results are listed in Table 1, 2 and 3.

* Subject no. 9 was split into two datasets because this subject resides at two locations.

\begin{tabular}{|c|c|c|c|}
\hline No. & Sex & Age & Address (in Japan) \\
\hline 1 & Male & 24 & $\begin{array}{l}\text { Yamato cho, Nakano ward, } \\
\text { Tokyo } \\
\text { Ninomiya cho, Naka gun, }\end{array}$ \\
\hline 2 & Male & 35 & Kanagawa \\
\hline 3 & Male & 57 & Toyo, Koto ward, Tokyo \\
\hline 4 & Male & 25 & $\begin{array}{l}\text { Ebisu south, Shibuya ward, } \\
\text { Tokyo } \\
\text { Higashiomiya, Minuma ward, }\end{array}$ \\
\hline 5 & Female & 23 & $\begin{array}{l}\text { Saitama city, Saitama } \\
\text { Ninomiya cho, Naka gun, }\end{array}$ \\
\hline 6 & Female & 33 & Kanagawa \\
\hline 7 & Male & 38 & $\begin{array}{l}\text { Kikunodai, Chofu city, Tokyo } \\
\text { Kamitakada, Nakano ward, }\end{array}$ \\
\hline 8 & Male & 24 & $\begin{array}{l}\text { Tokyo } \\
\text { Kusabana, Akiruno city, }\end{array}$ \\
\hline 9 & Female & 22 & Tokyo \\
\hline
\end{tabular}




\begin{tabular}{|c|c|c|c|}
\hline $9 \_2$ & Female & 22 & $\begin{array}{l}\text { Ichigaya sadohara cho, } \\
\text { shinjuku ward, Tokyo }\end{array}$ \\
\hline 10 & Female & 41 & $\begin{array}{l}\text { Takashimadaira, Itabashi } \\
\text { ward, Tokyo }\end{array}$ \\
\hline
\end{tabular}

Table 1. Attribute information of subjects. (Basic information)

\begin{tabular}{|c|c|c|c|c|}
\hline \multirow[b]{2}{*}{ No. } & \multicolumn{2}{|c|}{ Nearest station } & \multicolumn{2}{|c|}{$\begin{array}{r}\text { Information } \\
\text { between stations }\end{array}$} \\
\hline & Home & Workplace & $\begin{array}{l}\text { Time } \\
(\min )\end{array}$ & $\begin{array}{r}\text { Distance } \\
(\mathrm{km})\end{array}$ \\
\hline 1 & Koenji & Ichigaya & 20 & 7.9 \\
\hline 2 & Ninomiya & Torihama & 60 & 35.9 \\
\hline 3 & Kiba & $\begin{array}{l}\text { Shinyurigao } \\
\text { ka }\end{array}$ & 70 & 28.0 \\
\hline 4 & Ebisu & Ebisu & - & - \\
\hline 5 & $\begin{array}{l}\text { Higashiōmi } \\
\text { ya }\end{array}$ & Ōmiya & 20 & 5.0 \\
\hline 6 & Ninomiya & - & - & - \\
\hline 7 & $\begin{array}{l}\text { Tsutsujigao } \\
\text { ka }\end{array}$ & Tsukuba & 100 & 67.7 \\
\hline 8 & $\begin{array}{l}\text { Higashinak } \\
\text { ano }\end{array}$ & Yōga & 40 & 10.0 \\
\hline 9 & Hussa & Idabashi & 70 & 38.0 \\
\hline $9 \_2$ & Ichigaya & Idabashi & 2 & 1.50 \\
\hline 10 & Nishidai & Nihonbashi & 40 & 14.9 \\
\hline
\end{tabular}

Table 2. Attribute information of subjects. (Detailed information)

\begin{tabular}{r|rr}
\hline No. & Period of investigation & Days of daily life \\
\hline 1 & $2016 / 5 / 1-2016 / 7 / 31$ & 40 \\
2 & $2016 / 6 / 8-2016 / 7 / 17$ & 19 \\
3 & $2016 / 6 / 9-2016 / 7 / 24$ & 18 \\
4 & $2016 / 6 / 11-2016 / 7 / 17$ & 23 \\
5 & $2016 / 6 / 10-2016 / 7 / 17$ & 18 \\
6 & $2016 / 7 / 13-2016 / 7 / 28$ & 15 \\
7 & $2016 / 7 / 29-2016 / 9 / 13$ & 34 \\
8 & $2016 / 10 / 27-2016 / 12 / 27$ & 34 \\
9 & $2016 / 7 / 28-2016 / 9 / 22$ & 38 \\
92 & $2016 / 7 / 28-2016 / 9 / 22$ & 38 \\
10 & $2016 / 10 / 17-2016 / 12 / 17$ & 43 \\
\hline
\end{tabular}

Table 3. Attribute information of subjects. (Detailed information)

\subsection{Integration of Location-based data and Physical- Activity data}

Data on activity time, steps, calorie consumption, activity level, and moving distance were recorded with minuteby-minute resolution. Next, we extracted the origin and destination of each distinct trip and the time spent at each destination from the recorded GPS data. We also connected all trips in each day with that day's physicalactivity data. The average total steps per day for each subject were calculated based on these connected datasets. Figure 1 shows the divided walking contexts in sections in detail while also demonstrating that the subjects took an average of 10496 steps each day. Analysis of the geographic contexts in which these steps were taken shows the following breakdown: Indoor: 5458 steps (52\%), i. Outdoors: 4093 steps $(39 \%)$, and ii. within public transit stations: 945 steps $(9 \%)$, iii. These results can only be obtained by combining GPS and physicalactivity data.

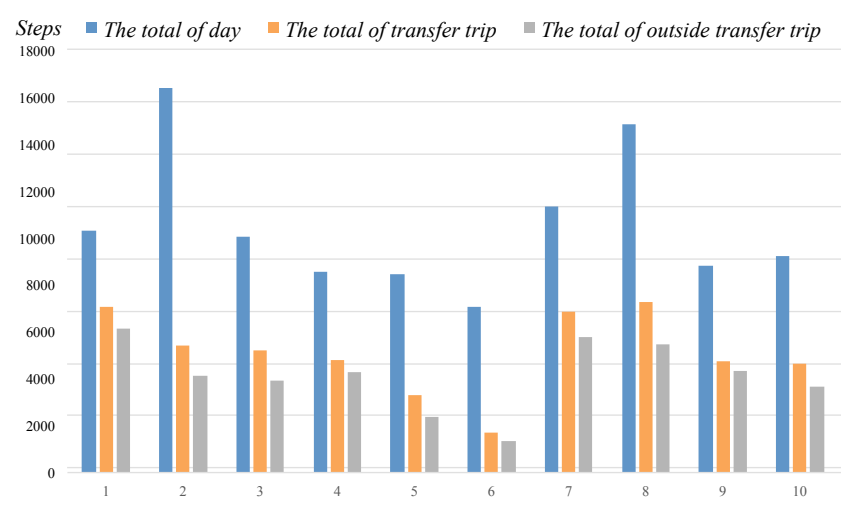

Figure 1. Classification of the number of steps per day of subjects.

\subsection{Comparison of Path Used In Everyday Travel and Shortest Path}

We checked whether subjects took the shortest path between the residence or workplace and the nearest transit station. According to a comparison of the shortest path and the number of times that all routes from home to a station were used (Figure 2), we found that subjects usually selected the shortest path on the way to work and selected diverse routes on their way home. When under time constraints to get to work punctually, we expect that people will usually select the shortest path. From our analysis of how frequently subjects took the shortest path, we confirmed that subjects rarely used the absolutely shortest path in any case. Results of analysis which these usage ratio of shortest path were taken shows the following breakdown: From home to station (way to work): $19 \%$, i. From station to workplace (way to work): $36 \%$, ii. From workplace to station (way home): $33 \%$, iii. From station to home (way home): $12 \%$, and iv. However, in cases the workplace was directly connected to the station, so some subjects had to select the shortest route.

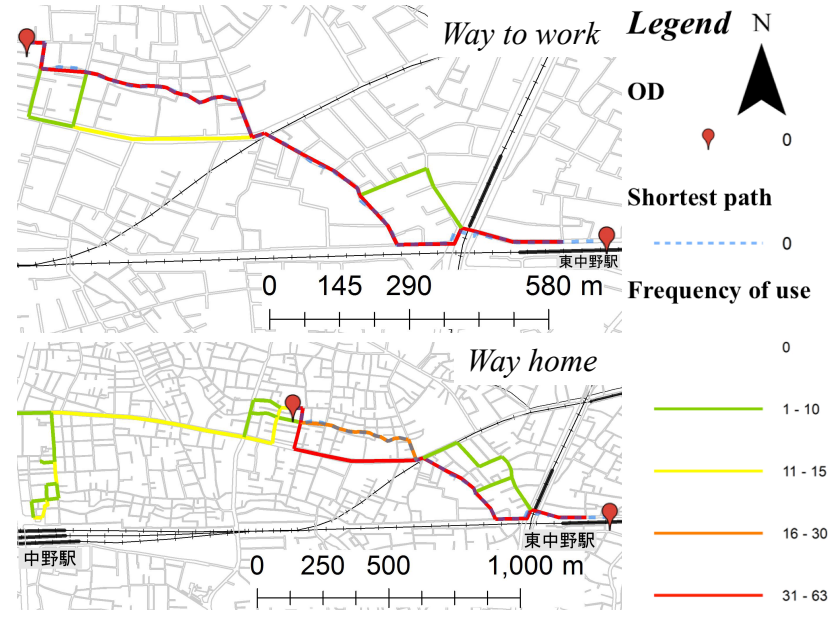

Figure 2. Number of frequency the route usage. 


\subsection{Features of Paths Used in Daily Life}

Figure 2 shows an example of the regular route taken by a subject (in red). We assessed the characteristics of the street design along this route to gain insight about the reason for not choosing the shortest route. The factors for this assessment were drawn from "Streets for People" (ref. Rudofsky B, 1969) and are listed in Table 4. Subjects tended to prefer wider roads on the way home from work and a narrower roads on their way to work. Narrower roads should be less desirable in terms of walkability; however, since these roads tend to have only light traffic, subjects can reach their destination faster. This led subjects to choose narrower roads for their trips to work. Conversely, on the way home from work, subjects tended to choose wider, busier roads.

\begin{tabular}{|c|c|c|c|}
\hline \multicolumn{2}{|l|}{ Factors } & $\begin{array}{r}\text { The } \\
\text { way } \\
\text { going }\end{array}$ & $\begin{array}{r}\text { The } \\
\text { way } \\
\text { back }\end{array}$ \\
\hline \multirow{12}{*}{$\begin{array}{l}\text { Around } \\
\text { home }\end{array}$} & Shortest path (distance) & 3 & 2 \\
\hline & Waterside & 2 & 2 \\
\hline & $\begin{array}{l}\text { The road for pedestrian } \\
\text { only/ priority }\end{array}$ & 1 & 1 \\
\hline & Width of the road (narrow) & 3 & 1 \\
\hline & Width of the road (wide) & 1 & 3 \\
\hline & Be crowded & 2 & 3 \\
\hline & Continuity/ Uniformaiton & 1 & 2 \\
\hline & Shortest path(time) & 2 & 2 \\
\hline & Roadside tree & 2 & 2 \\
\hline & Ups and downs & 1 & 1 \\
\hline & Shade & 0 & 0 \\
\hline & Streetlights & 0 & 1 \\
\hline \multirow{12}{*}{$\begin{array}{c}\text { Around } \\
\text { workpla } \\
\text { ce }\end{array}$} & Shortest path (distance) & 5 & 5 \\
\hline & Waterside & 4 & 4 \\
\hline & $\begin{array}{l}\text { The road for pedestrian } \\
\text { only/priority }\end{array}$ & 4 & 4 \\
\hline & Width of the road (narrow) & 3 & 1 \\
\hline & Width of the road (wide) & 0 & 2 \\
\hline & Be crowded & 0 & 0 \\
\hline & Continuity/ Uniformaiton & 1 & 1 \\
\hline & Shortest path (time) & 0 & 0 \\
\hline & Roadside tree & 0 & 0 \\
\hline & Ups and downs & 1 & 1 \\
\hline & Shade & 2 & 2 \\
\hline & Streetlights & 0 & 0 \\
\hline
\end{tabular}

Table 4. Evaluation results of the used path.

\section{Conclusion}

From our data, we conclude that the number of steps taken daily by residents of a city in which public transportation is prevalent was satisfactory to support healthy living. Approximately $40 \%$ steps were taken outdoors. Conventionally, the paths and roads examined in this study were designed to move people and things in the shortest distance or time. However, the present results suggest that the roads used in everyday activity are not always the shortest path but depend on a range of personal preferences. Hence, we conclude that the design of streets should be reconsidered to include a range of design goals tailored to the particular characteristics of an area and pedestrian use.

\section{References}

Fitbit, Inc.

“charge HR", < https://www.fitbit.com/jp/chargehr> (in Japanese), Online, Accessed Nov 2018.

Oba T, et al. (2013).

"Analysis of the Relationship between Urban Characters and Physical Activity Levels Based on the Travel

Behavior Data", Journal of the City Planning Institute of Japan, Vol.48 No.1, April, 2013.

ProtoGeo Oy.

"Moves", <https://moves-app.com> (shutting down), Online, Accessed Nov 2018.

Rudofsky B. (1969).

"Streets for People", Doubleday \& Company, ISBN: 978-0385042314, 1969. 